\title{
Synthesis, Characterization and Optimization of Oleyl Oleate Wax Ester Using Ionic Liquid Catalysts
}

\author{
Naowara Al-Arafi ${ }^{1}$, Nadia Salih ${ }^{2 *}$, and Jumat Salimon ${ }^{2}$ \\ ${ }^{1}$ Department of Chemistry, Faculty of Science, Benghazi University, P.O. Box 1308, Benghazi, Libya \\ ${ }^{2}$ Department of Chemical Sciences, Faculty of Science and Technology, Universiti Kebangsaan Malaysia, \\ 43600 Bangi, Selangor, Malaysia
}

* Corresponding author:

email:nadiaalnami@hotmail.com

Received: September 12, 2020

Accepted: November 11, 2020

DOI: $10.22146 / \mathrm{ijc} .59694$

\begin{abstract}
In this work, the synthesis of oleyl oleate wax ester using Brønsted acidic ionic liquid catalysts was carried out. Confirmation of oleyl oleate molecular structure has been performed using FTIR, NMR, and ESI-MS spectroscopies. The ability of ionic liquid catalysts for catalyzing the esterification reaction of oleic acid and oleyl alcohol to produce oleyl oleate was optimized. The ionic liquid catalyst ([NMP] $\left.\left[\mathrm{CH}_{3} \mathrm{SO}_{3}\right]\right)$ was found to be the best catalyst for the esterification reaction of oleic acid and oleyl alcohol compared with the other acidic ionic liquids studied. The optimal reaction conditions were determined at a reaction time of $8 \mathrm{~h}$; oleic acid to oleyl alcohol mole ratio of 1:1; ([NMP] $\left.\left[\mathrm{CH}_{3} \mathrm{SO}_{3}\right]\right)$ with $9.9 \mathrm{wt} . \%$; and reaction temperature of $90{ }^{\circ} \mathrm{C}$. Under these conditions, the percentage yield of oleyl oleate wax ester was $86 \%$.
\end{abstract}

Keywords: wax ester; Brønsted acidic ionic liquid catalyst; esterification reaction; oleic acid; oleyl alcohol

\section{- INTRODUCTION}

Esters have been used as biolubricants since the beginning of the nineteenth-century, in the form of natural esters in pig fat and whale oil. During World War II, a large number of synthetic fluids were developed, such as alcohol and long-chain acid esters that presented excellent low-temperature properties. The strongest effect of the ester group on the physical properties of lubricant is a decrease in its volatility and increase in its flashpoint. This is due to the strong dipole moment that keeps the ester molecules together. The ester group also affects other properties, such as thermal and hydrolytic stability, solvency, lubricity, and biodegradability [1]. The most important physical-chemistry properties of ester are viscosity, viscosity index (VI), pour point, lubricity, thermal, hydrolytic stabilities, and solvency. The main esters used as biolubricants are diesters, phthalates, trimethilates, $\mathrm{C}_{36}$ dimerates, polyolesters, and wax ester. Wax esters, consisting of long-chain fatty acids esterified to long-chain fatty alcohols, have potential applications as lubricants, plasticizers, and cosmetics [2]. These kinds of ester have excellent wetting properties at interfaces. Two good examples of naturally occurring wax esters are jojoba oil and sperm whale oil.

However, the supply of jojoba oil is inconsistent and sperm whale oil is diminishing, so a substitute for this wax ester is desired [3]. Esterification of carboxylic acids with alcohols using homogeneous and heterogeneous catalysts is well documented in the literature [4-6]. However, several limitations, such as an excess of the catalysts or amounts of reactants to achieve efficient conversion, removal of water during the reaction, long reaction times, and large amounts of effluent generation during work-up are associated with these processes [7]. The catalyst used in traditional esterification is mainly acidic homogeneous catalysts, such as sulphuric acid, as well as solid acid. Due to environmental concerns, the use of excess homogenous sulphuric acid can cause corrosion to the metallic equipment and this should be avoided. Solid acid catalysts have attracted considerable attention in recent years because of their significant advantages of eliminating corrosion, and environmental and toxicity 
problems. Apart from recyclability and reusability, the disadvantages of solid acid catalysts are low activity, easy deactivation, and difficulty in product separation [8-9].

Ionic liquid, a kind of environmentally friendly solvent and catalyst, has gained the attention of scholars from various fields such as synthesis, catalysis, separation, and electrochemistry, due to its tunable physical and chemical properties [10]. Ionic liquids are salts with a melting point lower than $100^{\circ} \mathrm{C}$. Ionic liquids are usually composed of an organic cation, typically containing nitrogen or phosphorus, and a weakly coordinating anion. Some of the most common cations are imidazolium, phosphonium, pyridinium, and ammonium, while some common anions are $\mathrm{BF}_{4}, \mathrm{PF}_{6}$, $\mathrm{CF}_{3} \mathrm{SO}_{3}$, and $\mathrm{N}\left(\mathrm{CF}_{3} \mathrm{SO}_{2}\right)_{2}$. Ionic liquids are nonflammable, thermally stable, exhibit negligible vapor pressure, and offer the potential for recyclability. For these reasons, the replacement of the current esterification protocols with a more environmentally benign process involving the use of ionic liquids was considered to be an area worthy of investigation. Deng et al. reported the esterification of carboxylic acids with alcohols in acidic chloroaluminate ionic liquid [11]. Some Brønsted acidic ionic liquids, including $\mathrm{SO}_{3} \mathrm{H}$ functionalized ionic liquid, ionic liquids with acidic counter anion, and protonated $\mathrm{N}$-alkylimidazolium ionic liquids have also been used in esterification reactions [1214]. Although elegant work has been done in this area; there still exist some drawbacks in the above-mentioned catalytic systems. Therefore, one of the driving forces for this research is the possibility of elucidating the merits of ionic liquids for esterification and preparing synthetic wax ester, which resembles naturally occurring waxes of commercial interest.

The objective of this work is to synthesis oleyl oleate wax ester by esterification reaction of oleic acid with oleyl alcohol using different Brønsted acidic ionic liquid catalysts MIM-PS, $\left[\mathrm{HSO}_{3}-\mathrm{Pmim}\right]\left[\mathrm{CH}_{3} \mathrm{SO}_{3}\right]$, [NMP] $\left[\mathrm{CH}_{3} \mathrm{SO}_{3}\right]$ and then optimizing the reaction with several variables that affect the yield, such as the molar ratio of oleic acid to oleyl alcohol, amount of catalyst, reaction time and reaction temperature.

\section{- EXPERIMENTAL SECTION}

\section{Materials}

Oleic acid (90\%) and oley alcohol (85\%) were purchased from Aldrich chemical company (Germany). Diethyl ether, 1,3-propane sulphone, toluene, and 1methyl imidazole were purchased from Systerm Chemical Company (Malaysia). Benzene and $\mathrm{N}$-methyl2-pyrrolidone were obtained from the ACE chemical company (Sydney). Methane sulphonic acid was purchased from J.T. Baker chemical company (USA). All other chemicals and reagents used in this study were analytical grade and used without further purification.

\section{Instrumentation}

Fourier transforms infrared spectroscopy (FTIR) was carried out using a Perkin Elmer Spectrum GX spectrophotometer in the range of $400-4000 \mathrm{~cm}^{-1}$. Nuclear magnetic resonance spectroscopy (NMR) for ${ }^{1} \mathrm{H}$ and ${ }^{13} \mathrm{C}$ was carried with model Joel FCP $400 \mathrm{MHz}$ with $\mathrm{CDCl}_{3}$ and $\mathrm{D}_{2} \mathrm{O}$ solvent. The electrospray ionization mass spectra (ESI-MS) were recorded on a Bruker MicroTOF-Q (German) mass spectrometer equipped with a Kd Scientific Apparatus syringe pump (USA).

\section{Procedure}

\section{Synthesis of 3-(1-methylimidazolium-3-yl) propane- 1-sulphonate (MIM-PS)}

In an ice-bath, 1-3-propane sulphone was dissolved in toluene and an equal mole of 1-methyl imidazole was dropped slowly with vigorous stirring. After dropping, the mixture was slowly heated up to room temperature and was stirred for $2 \mathrm{~h}$, and then the reaction mixture was filtered to obtain the white precipitate. The precipitate was washed three times with diethyl ether and was dried at $100{ }^{\circ} \mathrm{C}$ for $5 \mathrm{~h}$ to obtain MIM-PS as a white powder with $97 \%$ yield.

\section{Synthesis of 1-methyl-3-(3-sulphopropyl)-imidazolium methyl sulphate ([HSO - - $\mathrm{Pmim}]\left[\mathrm{CH}_{3} \mathrm{SO}_{3}\right]$ )}

First, MIM-PS was dissolved in water then an equal mole of methane sulphonic acid was dropped slowly at room temperature, after dropping, the reaction mixture was slowly heated up to $90^{\circ} \mathrm{C}$ and was stirred for $2 \mathrm{~h}$, and 
then the water was removed under vacuum $(5-10 \mathrm{~mm}$ $\mathrm{Hg})$ at $90{ }^{\circ} \mathrm{C}$, giving $\left(\left[\mathrm{HSO}_{3}-\mathrm{Pmim}\right]\left[\mathrm{CH}_{3} \mathrm{SO}_{3}\right]\right)$ as a light yellow viscous liquid yield $98 \%$.

\section{Synthesis of $\mathbf{N}$-methyl-2-pyrrolidonnium methyl sulfate ([NMP][CH $\left.\left.\mathrm{CH}_{3} \mathrm{SO}_{3}\right]\right)$}

Benzene $30 \mathrm{~mL}$ was mixed with $\mathrm{N}$-methyl-2pyrrolidone $(0.1 \mathrm{~mol}, 9.9 \mathrm{~g})$ in a $50 \mathrm{~mL}$ flask. Then, methane sulphonic acid $(0.1 \mathrm{~mol}, 9.6 \mathrm{~g})$ was dropped slowly into the flask within $30 \mathrm{~min}$ in an ice-bath. The reaction lasted for another $4 \mathrm{~h}$ at room temperature. Benzene was removed under reduced pressure and was further dried at $90{ }^{\circ} \mathrm{C}$ under $1-5 \mathrm{~mm} \mathrm{Hg}$ for $1 \mathrm{~h}$, giving ([NMP] $\left[\mathrm{CH}_{3} \mathrm{SO}_{3}\right]$ ) as a dark yellow viscous liquid yield $96 \%$.

\section{Synthesis of oleyl oleate wax ester}

A weighted amount of oleic acid ( $1 \mathrm{~mol})$, oleyl alcohol $(1,2$, and $3 \mathrm{~mol})$ and Brønsted acidic ionic liquid catalyst $(4.2,5.7,8.5,9.9,11.3$ and $15.6 \mathrm{wt} . \%)$ as a percentage of the weight of oleic acid were added to a flask reflux apparatus. The esterification reaction was typically carried out for $(2$, $4,6,8,10$, and $12 \mathrm{~h})$ at a temperature of $\left(30^{\circ} \mathrm{C}, 50^{\circ} \mathrm{C}, 70^{\circ} \mathrm{C}\right.$, $90^{\circ} \mathrm{C}, 100^{\circ} \mathrm{C}$, and $110^{\circ} \mathrm{C}$ ) with vigorous stirring. After the completion of the reaction, the reaction mixture was transferred into a separatory funnel and then $5 \mathrm{~mL}$ of methanol was added into the funnel, extraction was carried out. The aqueous layer was decanted and the product was dissolved with $20 \mathrm{~mL}$ of ethyl acetate, followed by $10 \mathrm{~mL}$ of water to remove the remaining methanol.
After the water layer was removed, the product was dried in a conical flask with a sufficient amount of $\mathrm{Na}_{2} \mathrm{SO}_{4}$ anhydrous. The hydrated $\mathrm{Na}_{2} \mathrm{SO}_{4}$ was filtered off, then, the product was rotary-evaporated to remove ethyl acetate at $77^{\circ} \mathrm{C}$, giving oleyl oleate as a viscous liquid.

\section{- RESULTS AND DISCUSSION}

\section{Characterization of Ionic Liquid Catalysts}

The structure of MIM-PS was characterized by the presence of asymmetric and symmetric $\mathrm{SO}_{2}$ stretching vibrations, which appeared as strong and weak bands at $1325 \mathrm{~cm}^{-1}$ (asy $\mathrm{SO}_{2}$ ), $1194 \mathrm{~cm}^{-1}$ (sy $\mathrm{SO}_{2}$ ), respectively, that were absent in 1-methyl imidazole. The $\mathrm{S}-\mathrm{O}$ stretching vibration was also detected at $747 \mathrm{~cm}^{-1}$. These special FTIR peaks indicated that the sulphonic group was successfully introduced in 1-methyl imidazole molecule. Fig. 1 shows the FTIR spectrum of MIM-PS. Furthermore, the ${ }^{1} \mathrm{H}$ and ${ }^{13} \mathrm{C}-\mathrm{NMR}$ spectra of MIM-PS are presented in Fig. 2 and 3, respectively. The most important peak in the ${ }^{1} \mathrm{H}-\mathrm{NMR}$ spectrum of the compound MIM-PS is the triplet peak related to $\mathrm{CH}_{2}-\mathrm{N}$, which was observed at $2.97 \mathrm{ppm}$. Besides, its ${ }^{13} \mathrm{C}-\mathrm{NMR}$ spectrum confirmed the presence of 7 carbon atoms in the MIM-PS, which indicates that the compound MIMPS was prepared successfully.

The structure of $\left[\mathrm{HSO}_{3}-\mathrm{Pmim}\right]\left[\mathrm{CH}_{3} \mathrm{SO}_{3}\right]$ has been confirmed by the presence of the bands representing the $\mathrm{S}=\mathrm{O}$ group $\left(1336,1196 \mathrm{~cm}^{-1}\right)$, OH group $\left(3443 \mathrm{~cm}^{-1}\right)$,

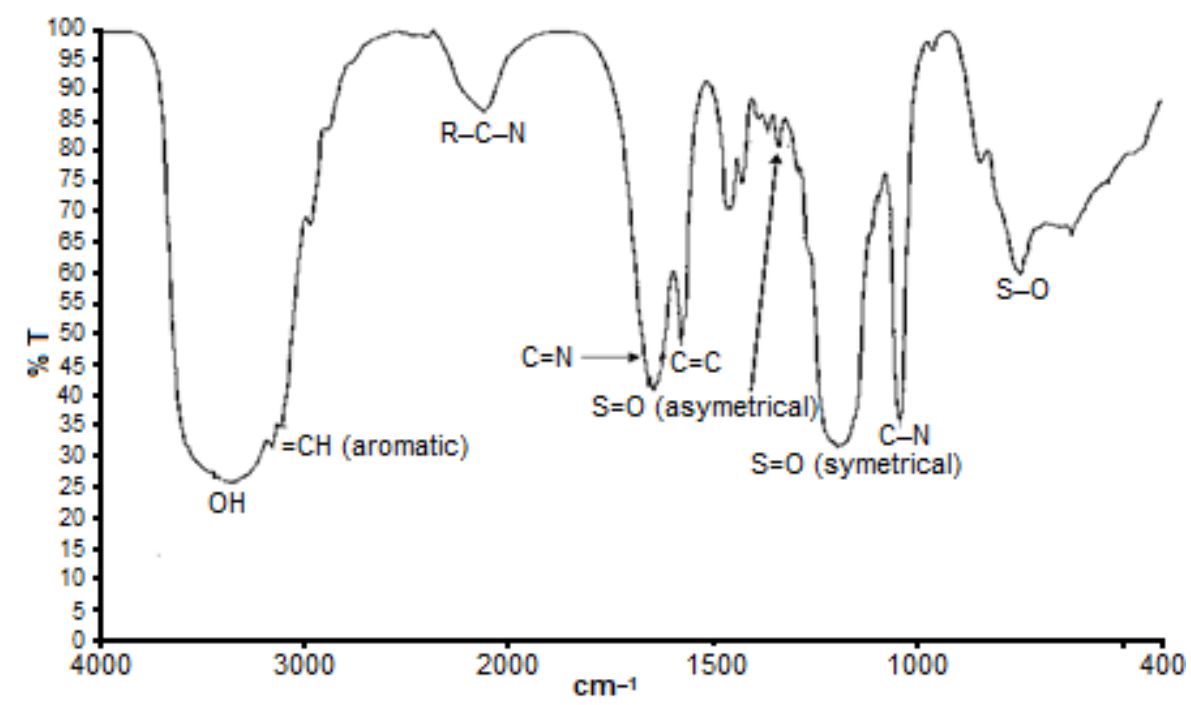

Fig 1. FTIR spectrum of MIM-PS 


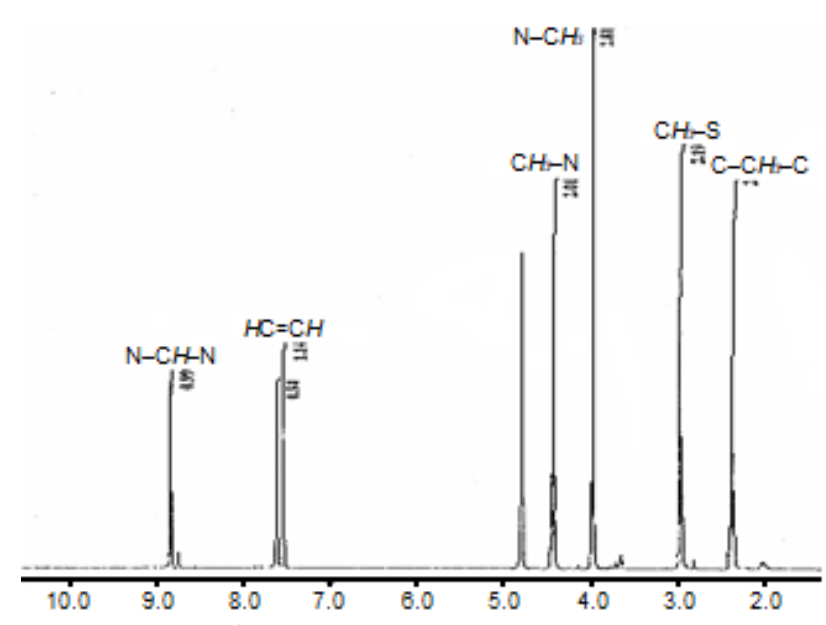

Fig 2. ${ }^{1} \mathrm{H}-\mathrm{NMR}$ spectrum of MIM-PS

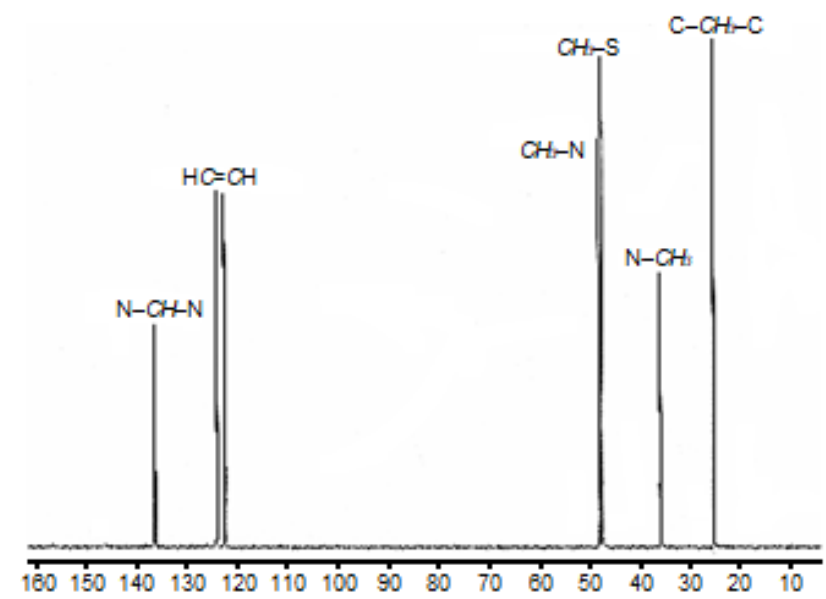

Fig 3. ${ }^{13} \mathrm{C}-\mathrm{NMR}$ spectrum of MIM-PS

S-O group $\left(748 \mathrm{~cm}^{-1}\right), \mathrm{C}=\mathrm{N}$ group $\left(1644 \mathrm{~cm}^{-1}\right), \mathrm{C}-\mathrm{N}$ group $\left(1042 \mathrm{~cm}^{-1}\right)$ and also $=\mathrm{CH}$ aromatic $(3110,3158$ $\mathrm{cm}^{-1}$ ) as shown in Fig. 4. The ${ }^{1} \mathrm{H}$ and ${ }^{13} \mathrm{C}$-NMR spectra of compound $\left[\mathrm{HSO}_{3}-\mathrm{Pmim}\right]\left[\mathrm{CH}_{3} \mathrm{SO}_{3}\right]$ were similar to ${ }^{1} \mathrm{H}$ and ${ }^{13} \mathrm{C}$-NMR spectra of MIM-PS but with significant signals in ${ }^{1} \mathrm{H}$ and ${ }^{13} \mathrm{C}$-NMR spectra of compound $\left[\mathrm{HSO}_{3}{ }^{-}\right.$ Pmim $]\left[\mathrm{CH}_{3} \mathrm{SO}_{3}\right]$ at $2.18 \mathrm{ppm}$ and $38.62 \mathrm{ppm}$, respectively. These peaks corresponded to methyl protons and carbon of methane sulphonic acid, which indicated that ionic liquid catalyst $\left[\mathrm{HSO}_{3}-\mathrm{Pmim}\right]\left[\mathrm{CH}_{3} \mathrm{SO}_{3}\right]$ was correctly synthesized. Furthermore, the signal due to the $\mathrm{OH}$ group (11-12 ppm) was not observed in the ${ }^{1} \mathrm{H}-\mathrm{NMR}$ spectrum of $\left[\mathrm{HSO}_{3}-\mathrm{Pmim}\right]\left[\mathrm{CH}_{3} \mathrm{SO}_{3}\right]$ due to the deuterium exchange where $\mathrm{D}_{2} \mathrm{O}$ was used as the ${ }^{1} \mathrm{H}$-NMR solvent, as shown in Fig. 5 and 6.

Fig. 7 shows the representative FTIR spectrum of [NMP] $\left[\mathrm{CH}_{3} \mathrm{SO}_{3}\right]$. The characteristic signals in the FTIR

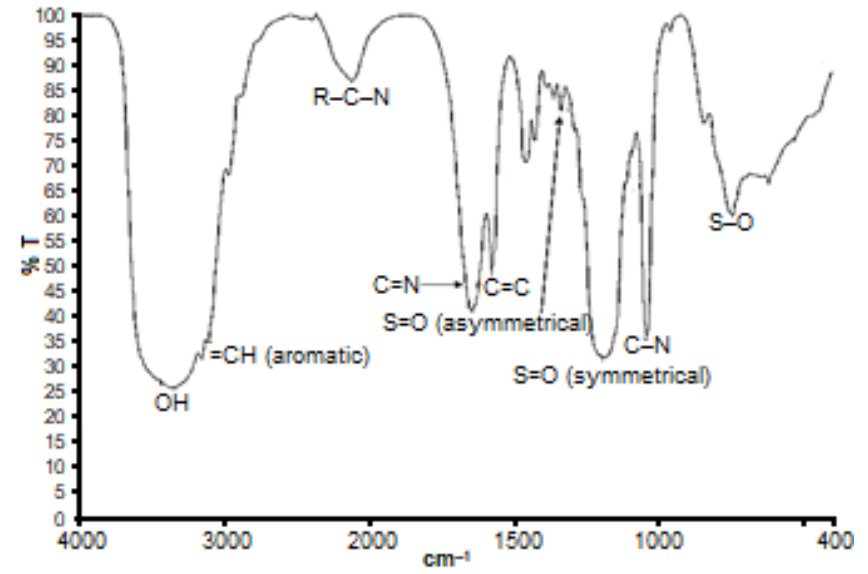

Fig 4. FTIR spectrum of $\left[\mathrm{HSO}_{3}-\mathrm{Pmim}\right]\left[\mathrm{CH}_{3} \mathrm{SO}_{3}\right]$

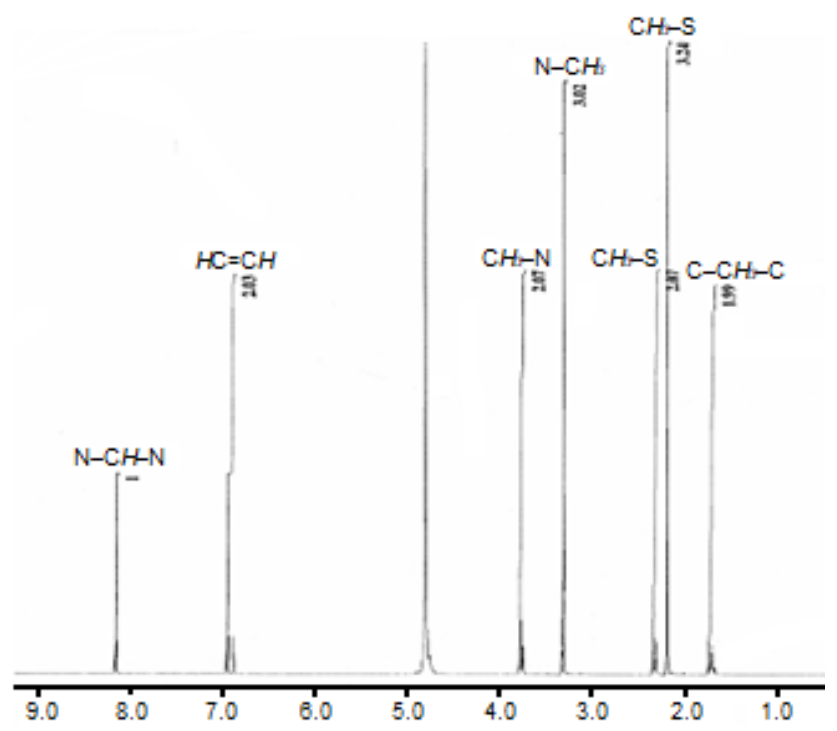

Fig 5. ${ }^{1} \mathrm{H}-\mathrm{NMR}$ spectrum of $\left[\mathrm{HSO}_{3}-\mathrm{Pmim}\right]\left[\mathrm{CH}_{3} \mathrm{SO}_{3}\right]$

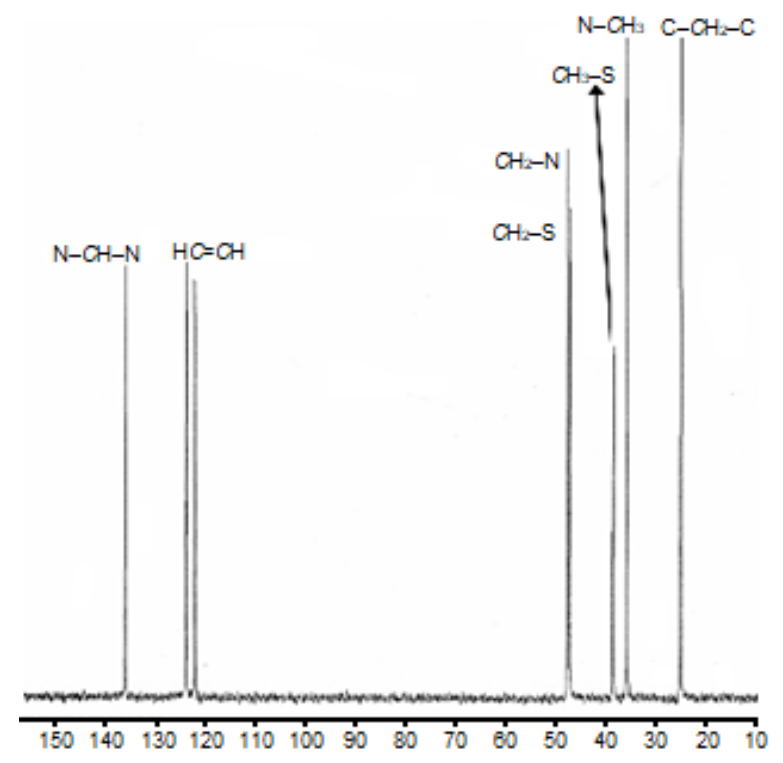

Fig 6. ${ }^{13} \mathrm{C}-\mathrm{NMR}$ spectrum of $\left[\mathrm{HSO}_{3}-\mathrm{Pmim}\right]\left[\mathrm{CH}_{3} \mathrm{SO}_{3}\right]$ 
spectrum of $[\mathrm{NMP}]\left[\mathrm{CH}_{3} \mathrm{SO}_{3}\right]$ at 1200,1307 , and $789 \mathrm{~cm}^{-1}$ corresponded to the $\mathrm{SO}_{3}$ and $\mathrm{S}-\mathrm{O}$ groups, while the signal at $1652 \mathrm{~cm}^{-1}$ showed the $\mathrm{C}=\mathrm{O}$ group of $\mathrm{N}$-methyl-2pyrrolidon. This observation proved the success of the synthesis of the Brønsted acidic ionic liquid catalyst [NMP] $\left[\mathrm{CH}_{3} \mathrm{SO}_{3}\right]$. The NMR spectra data gave additional support for the composition of the compound. The observed changes are evidence of the reaction that occurred because the chemical shift of a compound is deeply dependent on its electronic environment. Fig. 8 and 9 indicate the ${ }^{1} \mathrm{H}$ and ${ }^{13} \mathrm{C}-\mathrm{NMR}$ spectra of ([NMP] $\left.\left[\mathrm{CH}_{3} \mathrm{SO}_{3}\right]\right)$, respectively. The result of the ${ }^{1} \mathrm{H}-$ $\mathrm{NMR}$ spectrum of $[\mathrm{NMP}]\left[\mathrm{CH}_{3} \mathrm{SO}_{3}\right]$ confirmed the appearance of the proton signals of $\mathrm{CH}_{3} \mathrm{SO}_{3} \mathrm{H}$ at about $2.56 \mathrm{ppm}$. Furthermore, at about $\delta 11.70 \mathrm{ppm}$, the proton signal of $\mathrm{N}-\mathrm{H}$ as a broad signal appeared. Moreover, the $\mathrm{C}=\mathrm{O}$ resonance group of the product appeared at about $174.60 \mathrm{ppm}$, while the $\mathrm{CH}_{3}$ group of compound $\mathrm{CH}_{3} \mathrm{SO}_{3} \mathrm{H}$ was detected at $39.90 \mathrm{ppm}$, which means that the reaction between $\mathrm{N}$-methyl-2-pyrrolidone and methane sulphonic acid had taken place.

\section{Effect of Various Ionic Liquid Catalysts}

Initially, the esterification reaction between oleic acid and oleyl alcohol at $90{ }^{\circ} \mathrm{C}$ under solvent-free conditions was tested. Three existing Brønsted acidic ionic liquids, including $\mathrm{MIM}-\mathrm{PS}, \quad\left[\mathrm{HSO}_{3}{ }^{-}\right.$ Pmim] $\left[\mathrm{CH}_{3} \mathrm{SO}_{3}\right]$, and $[\mathrm{NMP}]\left[\mathrm{CH}_{3} \mathrm{SO}_{3}\right]$ were used. Table 1 shows the yield percent of the experiments carried out under the same conditions. [NMP] $\left[\mathrm{CH}_{3} \mathrm{SO}_{3}\right]$ proved to be active, leading to a $45.41 \%$ yield of oleyl oleate within $2 \mathrm{~h}$ when 9.9 wt.\% ionic liquid was used (percentage of the weight of oleic acid). [ $\left.\mathrm{HSO}_{3}-\mathrm{Pmim}\right]\left[\mathrm{CH}_{3} \mathrm{SO}_{3}\right]$ could also be used as a catalyst to promote the esterification reaction, but its activity seems to be slightly inferior compared with that of ([NMP] $\left.\left[\mathrm{CH}_{3} \mathrm{SO}_{3}\right]\right)$. However, repeating the reaction using MIM-PS only produced 32\% of oleyl oleate at the same temperature and reaction time due to its hydrophobic nature which leads to catalyst deactivation. In general, the percentage yields of oleyl oleate produced from the esterification process catalyzed by ionic liquids is lower compared to homogeneous acidic catalysts such as sulfuric acid (94\%), phosphoric acid (52.7\%), perchloric acid 54.9) and p-TSA (70\%) for the same $2 \mathrm{~h}$ reaction time [15] and by using Lipozyme (75.66\%) for $5 \mathrm{~h}$ reaction time [16]. However, because of the foregoing research, ([NMP] $\left[\mathrm{CH}_{3} \mathrm{SO}_{3}\right]$ ) should be a suitable catalyst for the esterification reaction of oleic acid

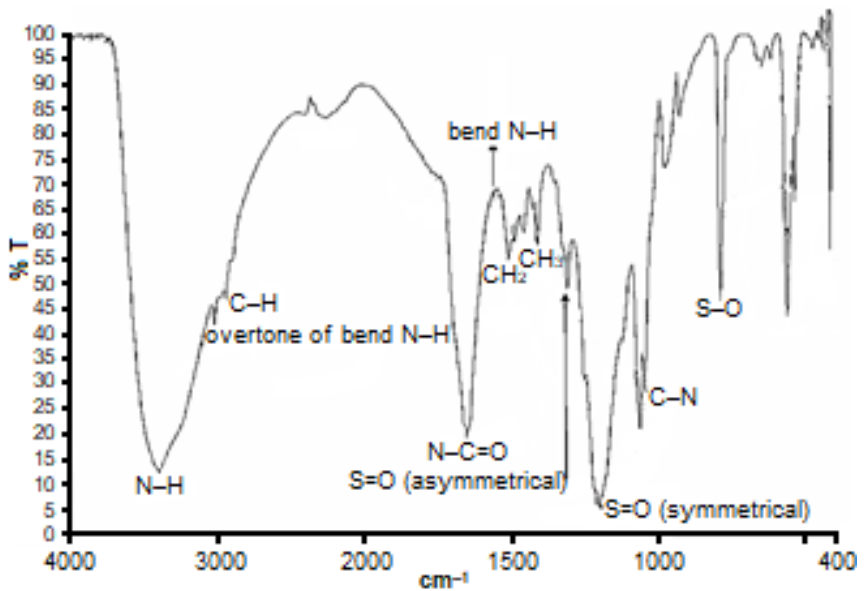

Fig 7. FTIR spectrum of [NMP] $\left[\mathrm{CH}_{3} \mathrm{SO}_{3}\right]$

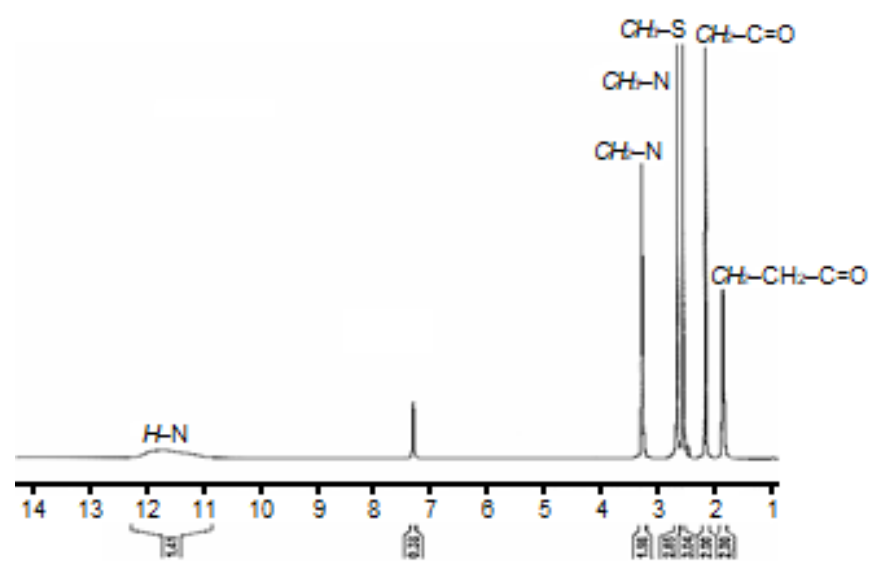

Fig 8. ${ }^{1} \mathrm{H}-\mathrm{NMR}$ spectrum of $[\mathrm{NMP}]\left[\mathrm{CH}_{3} \mathrm{SO}_{3}\right]$

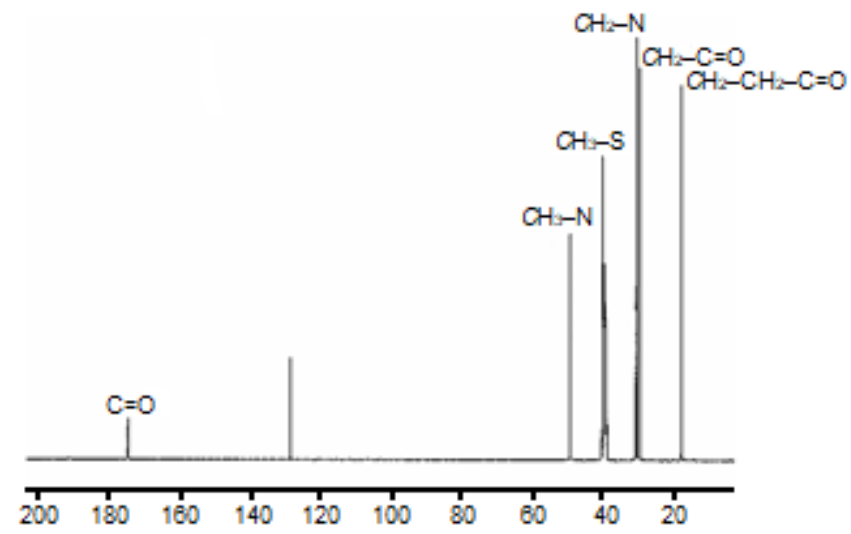

Fig 9. The ${ }^{13} \mathrm{C}$ NMR spectrum of $[\mathrm{NMP}]\left[\mathrm{CH}_{3} \mathrm{SO}_{3}\right]$ 
Table 1. The yields $\%$ of oleyl oleate wax ester based on the ionic liquid catalyst used

\begin{tabular}{lccc}
\hline \multirow{2}{*}{ Duration } & \multicolumn{3}{c}{ Ester yield (\%) } \\
\cline { 2 - 4 } & $\mathrm{MIM}-\mathrm{PS}$ & $\left(\left[\mathrm{HSO}_{3}-\mathrm{Pmim}\right]\left[\mathrm{CH}_{3} \mathrm{SO}_{3}\right]\right)$ & $\left([\mathrm{NMP}]\left[\mathrm{CH}_{3} \mathrm{SO}_{3}\right]\right)$ \\
\hline $2 \mathrm{~h}$ & $32.00 \pm 3.1$ & $35.00 \pm 3.28$ & $45.41 \pm 2.15$ \\
\hline
\end{tabular}

with oleyl alcohol to produce oleyl oleate. It offers significant improvements concerning the yield of products, simplicity in operation, and green aspects by avoiding toxic catalysts and solvents.

The esterification reaction proceeds through the addition of a proton and nucleophilic attack of the alcohol give a tetrahedral intermediate followed by dehydration. The three steps are all typical acid-catalyzed reactions. Therefore, the outcome of the esterification reaction depends very much on the acidity of the catalyst [17-18]. However, acidity determinations based on room temperature Brønsted acidic ionic liquids are a relatively new subject. The determination of the acidity of ionic liquid catalysts used in this research has not even been considered yet. A commonly used method to evaluate the acidity of acid in solution is the Hammett method [19], wherein a basic indicator has been used to trap the dissociative proton. The properties of the protons depend on both the nature of the solvent and the concentration of the chosen acid. The acidity was evaluated from the determination of the Hammett acidity functions, using UV-visible spectroscopy. In the present case, this method consists of evaluating the protonation extent of the uncharged indicator base (named I) in solution, in terms of the measurable ratio $[\mathrm{I}] /\left[\mathrm{IH}^{+}\right]$. In a given solvent $(\mathrm{S})$, assumed as being dissociating, the Hammett function $\left(\mathrm{H}_{0}\right)$ is defined as (Eq. (1)):

$$
\mathrm{H}_{0}=\mathrm{pK}(\mathrm{I})_{\mathrm{aq}}+\log \left([\mathrm{I}]_{\mathrm{s}} /\left[\mathrm{IH}^{+}\right]_{\mathrm{s}}\right)
$$

For comparison, the acidities of these three Brønsted acidic ionic liquid catalysts were examined using 4- nitroaniline (Hammett constant is 0.99) as an indicator in distilled water; the results are shown in Table 2. The maximal absorbance of the unprotonated form of the indicator was observed at $380 \mathrm{~nm}$ in $\mathrm{H}_{2} \mathrm{O}$. When an ionic liquid was added, the absorbance of the unprotonated form of indicator decreased. As shown in Fig. 10, the absorbance of the unprotonated form of the indicator on three ionic liquid catalysts decreased as follows: MIM$\mathrm{PS}>\left(\left[\mathrm{HSO}_{3}-\mathrm{Pmim}\right]\left[\mathrm{CH}_{3} \mathrm{SO}_{3}\right]\right)>\left(\left[(\mathrm{NMP}]\left[\mathrm{CH}_{3} \mathrm{SO}_{3}\right]\right)\right.$. By taking 4-nitroaniline as the initial reference (blank) the total unprotonated form of the indicator (when no acid is added to $\mathrm{H}_{2} \mathrm{O}$ solution, spectrum a), the ratio $[\mathrm{I}] /\left[\mathrm{IH}^{+}\right]$was determined from the measured absorbances after each ionic liquid (spectra $\mathrm{b}-\mathrm{d}$ ), and then the Hammett function $\left(\mathrm{H}_{0}\right)$ was calculated.

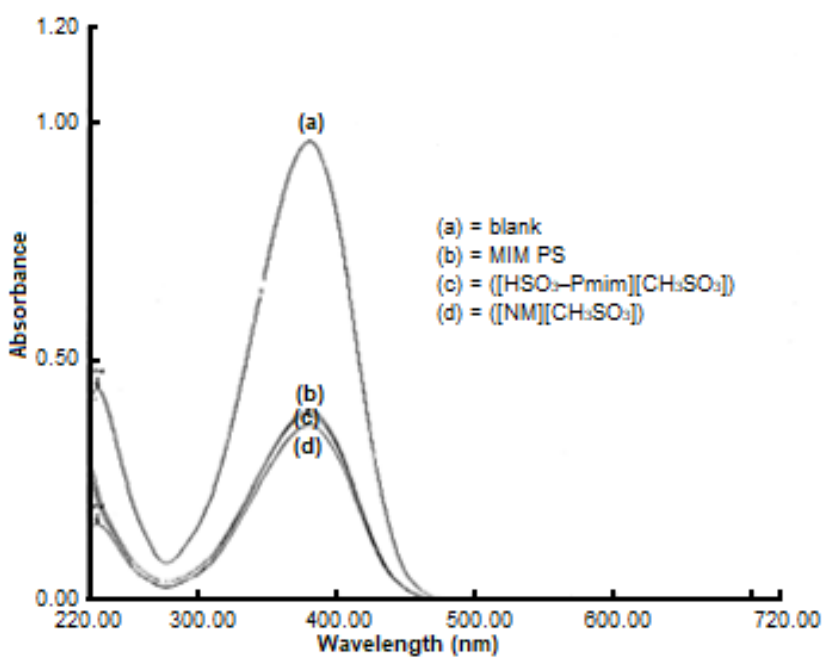

Fig 10. Absorption spectra of 4-nitroaniline for Brønsted acidic ionic liquids in water

Table 2. $\mathrm{H}_{0}$ values of various Brønsted acidic ionic liquid catalyst ${ }^{\text {[a] }}$

\begin{tabular}{lcccl}
\hline Ionic liquids & Absorbance $[\mathrm{AU}]$ & {$[\mathrm{I}] \%$} & {$\left[\mathrm{HI}^{+}\right] \%$} & $\mathrm{H}_{0}$ \\
\hline 4-nitroaniline & 0.962 & 100 & 0 & 0 \\
MIM-PS & 0.39 & 41 & 59 & 0.8 \\
{$\left[\mathrm{HSO}_{3}-\mathrm{Pmim}\right]\left[\mathrm{CH}_{3} \mathrm{SO}_{3}\right]$} & 0.388 & 40 & 59.7 & 0.82 \\
{$\left[(\mathrm{NMP}]\left[\mathrm{CH}_{3} \mathrm{SO}_{3}\right]\right.$} & 0.36 & 37.4 & 62.6 & 0.76 \\
\hline
\end{tabular}

${ }^{[a]}$ Concentration: $10 \mathrm{mmol} / \mathrm{L}$ 
The smallest $\mathrm{H}_{0}$ was obtained in a $10 \mathrm{mmol} / \mathrm{L} \mathrm{H}_{2} \mathrm{O}$ solution of $\left[(\mathrm{NMP}]\left[\mathrm{CH}_{3} \mathrm{SO}_{3}\right]\right.$, which indicated that Brønsted acidic ionic liquid [(NMP] $\left[\mathrm{CH}_{3} \mathrm{SO}_{3}\right]$ exhibits stronger acidity than the two other ionic liquid catalysts used in this work. The acidity of $\left[\mathrm{HSO}_{3}-\mathrm{Pmim}\right]\left[\mathrm{CH}_{3} \mathrm{SO}_{3}\right]$ is almost equal with MIM-PS, but slightly inferior compared with [(NMP] $\left[\mathrm{CH}_{3} \mathrm{SO}_{3}\right]$. The result by using ionic liquid catalyst $\left[(\mathrm{NMP}]\left[\mathrm{CH}_{3} \mathrm{SO}_{3}\right]\right.$ shows the highest acidity, therefore a high \% yield of oleyl oleate wax ester was obtained when the reaction was carried out using this catalyst.

\section{Effect of the Reaction Time}

Fig. 11 shows the effect of the reaction time on the esterification reaction of oleic acid with oleyl alcohol.

The reactions were carried out within 2, 4, 6, 8, 10, $12 \mathrm{~h}$. The other reaction conditions were as follows: substrates oleic acid and oleyl alcohol molar ratio of 1:1; amount catalyst of $9.9 \mathrm{wt} . \%$ as a percentage of the weight of the oleic acid; reaction temperature, $90^{\circ} \mathrm{C}$, and type of catalyst, ([(NMP] $\left.\left[\mathrm{CH}_{3} \mathrm{SO}_{3}\right]\right)$. The \% yield of oleyl oleate wax ester increased with the increasing reaction time. ( $\left[(\mathrm{NMP}]\left[\mathrm{CH}_{3} \mathrm{SO}_{3}\right]\right)$ gave the highest percentage yield within a reaction period of $8 \mathrm{~h}(86 \%)$. Thereafter, the percentage yield of oleyl oleate decreased (47.37\%) at $10 \mathrm{~h}$. This behavior may be due to the production of water molecules, which increased the solvation process of the catalyst. According to Trubiano et al. [20], the presence of water only has an unfavorable effect on the equilibrium conversion. Since water is one of the products in the esterification reaction, it can promote the reverse hydrolysis reaction in the process. It is important to remove water during the reaction to achieve a high product yield. After $10 \mathrm{~h}$ the \% yield of oleyl oleate was relatively reduced (41.95\%). This may be due to the reaction having achieved the equilibrium state where the rate of the forward reaction is equal to the rate of backward reaction. Hence, the concentration of the product was unchanged.

\section{Effect of Molar Ratio of Substrates}

To study the effect of the molar ratio in the esterification reaction of oleic acid with oleyl alcohol, the reaction was done using $1: 1,1: 2$, and 1:3 of oleic acid to oleyl alcohol under the following conditions: reaction time of $8 \mathrm{~h}$; the amount of catalyst, $9.9 \mathrm{wt} . \%$ as a percentage of the weight of the oleic acid; reaction temperature, $90{ }^{\circ} \mathrm{C}$, and type of catalyst, $\left[(\mathrm{NMP}]\left[\mathrm{CH}_{3} \mathrm{SO}_{3}\right]\right.$. The effect of the molar ratio of substrates on the esterification reaction is shown in Fig. 12. The optimal molar ratio of oleic acid to oleyl alcohol was $1: 1$, which gave $86 \%$ of oleyl oleate. Increasing the molar ratio of oleic acid to oleyl alcohol beyond this molar ratio 1:1 would decrease the esterification activity.

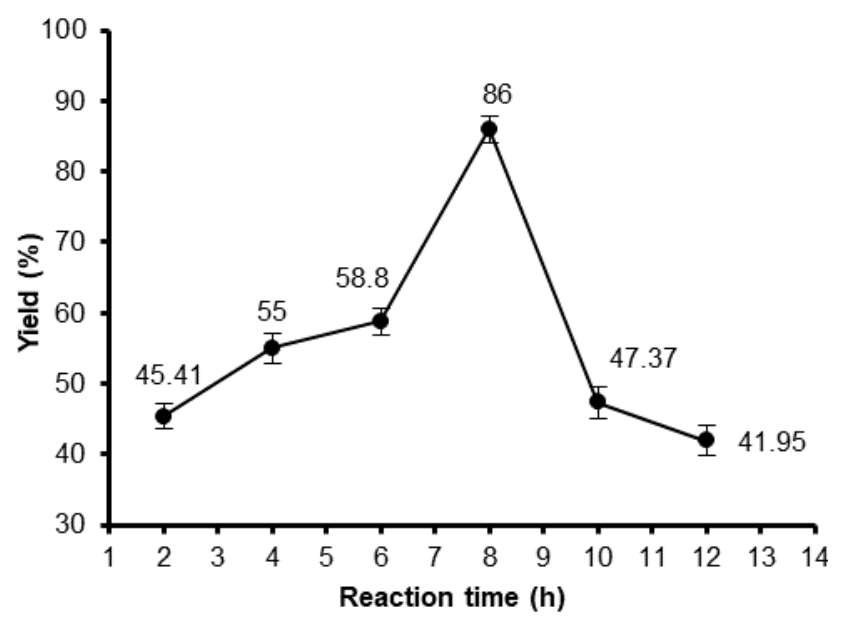

Fig 11. Effect of reaction time on the percentage yield of oleyl oleate wax ester. Values represent means \pm SD of three of triplicate determinations

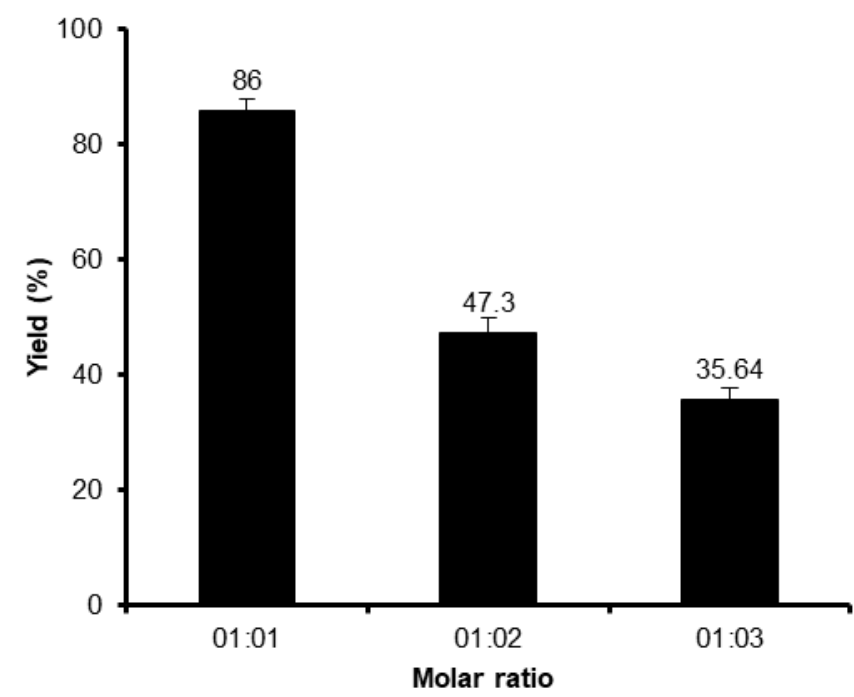

Fig 12. Effect of molar ratio of oleic acid and oleyl alcohol on the percentage yield of oleyl oleate wax ester. Values represent means \pm SD of three of triplicate determinations 
This observation may reflect that an excess of oleyl alcohol would hinder the interaction frequency between the substrate and the catalyst [21-23]. Due to the high concentrations of oleyl alcohol, the viscosity of the reaction mixture surrounding the catalyst is increased, leading to ineffective mixing of substrates, thus decrease the rate of reaction.

\section{Effect of Amount of Catalyst}

The influence of a varying amount of $\left[(\mathrm{NMP}]\left[\mathrm{CH}_{3} \mathrm{SO}_{3}\right]\right.$ corresponding to $4.2,5.7,8.5,9.9,11.3$, and $15.6 \mathrm{wt} . \%$ as a percentage of the weight of the oleic acid on the esterification reaction of oleyl alcohol and oleic acid at $90^{\circ} \mathrm{C}$, during $8 \mathrm{~h}$ using $1 \mathrm{~mol}$ of oleic acid: 1 mol oleyl alcohol is shown in Fig. 13. The \% yield increased from $4.2 \%$ (28.4\%) to $9.9 \%$ (86\%) and decreased when the amount of catalyst increased to $11.3 \%$ (67.52). The amount of catalyst at $9.9 \%$ was sufficient to catalyze this esterification reaction. This result shows that an excess of catalyst amount did not contribute to the increase in the percentage yield, and, that, sometimes, it would decrease the yield of the product. This is due to the solvation of water from the Brønsted acidic ionic liquid catalyst becoming less, meaning that the water will excess on pre-condition and this will make the reversible reaction occur [24].

\section{Effect of Reaction Temperature}

Changes in the reaction temperature can affect the activity and stability of the catalyst and thus the rate of reaction. Fig. 14 shows the influence of temperature on the esterification reaction within a temperature range of $30,50,70,90,100$, and $110^{\circ}$. The other reaction conditions were as follows: reaction time, $8 \mathrm{~h}$; the amount of catalyst, $9.9 \mathrm{wt} . \%$ as a percentage of the weight of the oleic acid; substrates molar ratio, 1:1 of oleic acid to oleyl alcohol and type of catalyst, ([(NMP] $\left.\left[\mathrm{CH}_{3} \mathrm{SO}_{3}\right]\right)$. Initially, the $\%$ yield of oleyl oleate increased with the increasing temperature reaching the maximum at $90{ }^{\circ} \mathrm{C}(86 \%)$. This is because the energy received from the heat of higher temperature was used to increase the frequency of collision between the molecules thereby increasing the rate of reaction. However, the percentage yield started to decline to $56.39 \%$ at $100{ }^{\circ} \mathrm{C}$ and to $54.28 \%$ at $110{ }^{\circ} \mathrm{C}$. Water



Fig 13. Effect of amount of catalyst on the percentage yield of oleyl oleate wax ester. Values represent means \pm $\mathrm{SD}$ of three of triplicate determinations

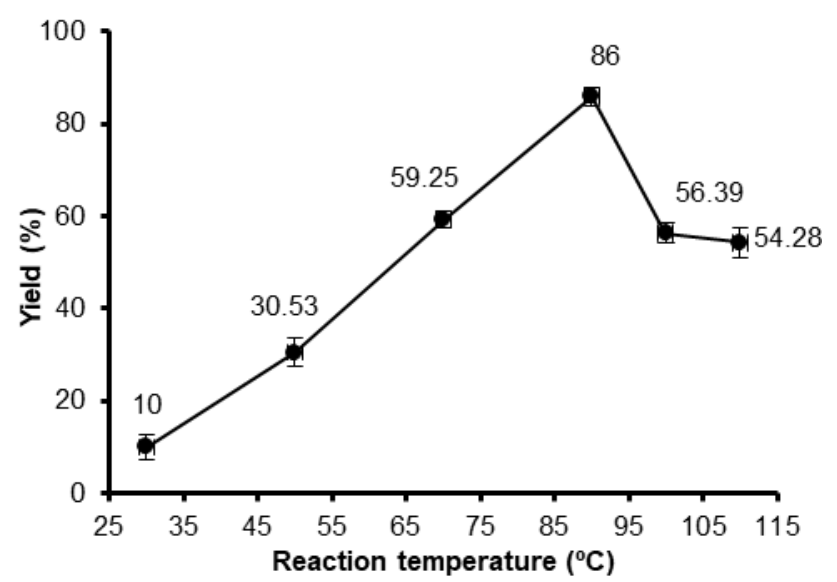

Fig 14. Effect of temperature on the percentage yield of oleyl oleate wax ester. Values represent means \pm SD of three of triplicate determinations

content simultaneously formed during the esterification reaction increased to higher temperatures, and better dissolved in the Brønsted acidic ionic liquid. This consequently, diluted the ionic liquid catalyst and greatly decreased the viscosity and acidity [25].

\section{- CONCLUSION}

The Brønsted acidic ionic liquid [ $\mathrm{NMP}]\left[\mathrm{CH}_{3} \mathrm{SO}_{3}\right]$ is non-flammable, easy to synthesize, thermally stable, and exhibits negligible vapor pressure. The $[\mathrm{NMP}]\left[\mathrm{CH}_{3} \mathrm{SO}_{3}\right]$ as an esterification catalyst, has many advantages in which the Brønsted acidic ionic liquid 
([NMP] $\left[\mathrm{CH}_{3} \mathrm{SO}_{3}\right]$ ) exhibits good catalytic performance. The $[\mathrm{NMP}]\left[\mathrm{CH}_{3} \mathrm{SO}_{3}\right]$ loads which are 9.9 wt.\% (as a percentage of the weight of oleic acid) can be used to catalyze the esterification process to produce esters with high yield. Also, the procedure used for the preparation of $[\mathrm{NMP}]\left[\mathrm{CH}_{3} \mathrm{SO}_{3}\right]$ is quite easy and inexpensive. The preliminary acidity determinations of three Brønsted acidic ionic liquids used in this research revealed that the acidities of the ionic liquids play a determining role in the rate acceleration of the esterification reaction. The esterification reaction could be done at moderate temperature; a high \% yield of oleyl oleate wax ester was obtained. Therefore, using $[\mathrm{NMP}]\left[\mathrm{CH}_{3} \mathrm{SO}_{3}\right]$ will decrease the cost of production. This methodology offers significant improvements concerning the yield of products, simplicity in operation, and green aspects by avoiding toxic catalysts and solvents.

\section{- ACKNOWLEDGMENTS}

The authors acknowledge the Universiti Kebangsaan Malaysia for funding (Code UKMGUPNBT-08-27-113 and UKM-OUP-NBT-29-150/2011) and the direct contributions of the support staff from the Department of Chemical Sciences, the Faculty of Science and Technology, Universiti Kebangsaan Malaysia.

\section{- REFERENCES}

[1] da Silva, J.A.C., 2011, "Biodegradable lubricants and their production via chemical catalysis" in Tribology - Lubricants and Lubrication, Eds. Kuo, C.H., IntechOpen, Rijeka, Croatia, 185-200.

[2] Cheng, D., 2013, Wax ester biosynthetic pathway, Dissertations, Department of Biochemistry, Biophysics and Molecular Biology, Iowa State University, US.

[3] Samidin, S., Salih, N., and Salimon, J., 2021, Synthesis and characterization of trimethylolpropane based esters as green biolubricant basestock, Biointerface Res. Appl. Chem., 11 (5), 13638-13651.

[4] Liu, T., Peng, X., Chen, Y., Zhang, J., Jiao, C., and Wang, H., 2020, Solid-phase esterification between poly(vinyl alcohol) and malonic acid and its function in toughening hydrogels, Polym. Chem., 11 (29), 4787-4797.

[5] Weng, S.S., Chen, F.K., and Ke, C.S., 2013, Direct esterification of carboxylic acids with alcohols catalyzed by iron(III) acetylacetonate complex, Synth. Commun., 43 (19), 2615-2621.

[6] Naik, S., Kavala, V., Gopinath, R., and Patel, B.K., 2006, Tetrabutylammonium tribromide mediated condensation of carboxylic acids with alcohols, Arkivoc, 2006 (1), 119-127.

[7] Bartlewicz, O., Dąbek, I., Szymańska, A., and Maciejewski, H., 2020, Heterogeneous catalysis with the participation of ionic liquids, Catalysts, 10 (11), 1227.

[8] Liang, S.T., Wang, H.Z., and Liu, J., 2018, Progress, Mechanism and application of liquid metal catalysis system: A review, Chem. Eur. J., 24 (67), 1761617626.

[9] Gao, P., Zhang, L., Li, S., Zhou, Z., and Sun, Y., 2020, Novel heterogeneous catalysts for $\mathrm{CO}_{2}$ hydrogenation to liquid fuels, ACS Cent. Sci., 6 (10), 1657-1670.

[10] Soleimani, O., 2020, Properties and applications of ionic liquids, J. Chem. Rev., 2 (3), 169-181.

[11] Deng, Y., Shi, F., Beng, J., and Qiao, K., 2001, Ionic liquid as a green catalytic reaction medium for esterification, J. Mol. Catal. A: Chem., 165 (1-2), 3336.

[12] Vafaeezadeh, M., and Alinezhad, H., 2016, Brønsted acidic ionic liquids: Green catalysts for essential organic reactions, J. Mol. Liq., 218, 95-105.

[13] Zhang, T., Li, X., Song, H., and Yao, S., 2019, Ionic liquid-assisted catalysis for glycosidation of two triterpenoid sapogenins, New J. Chem., 43 (43), 16881-16888.

[14] Al-Arafi, N., and Salimon, J., 2012, Production of oleic acid based wax ester using acidic homogeneous catalysts, J. Chem., 9, 181249.

[15] Sardar, S., Wilfred, C.D., and Leveque, J.M., 2017, One-pot Mannich base synthesis using task specific protic ionic liquids, Malays. J. Anal. Sci., 21 (5), 1203-1209. 
[16] Salminen, E., Virtanen, P., and Mikkola, J.P., 2014, Alkaline ionic liquids applied in supported ionic liquid catalyst for selective hydrogenation of citral to citronellal, Front. Chem., 2, 3.

[17] Polesso, B.B., Bernard, F.L., Ferrari, H.Z., Duarte, E.A., Vecchia, F.D., and Einloft, S., 2019, Supported ionic liquids as highly efficient and low-cost material for $\mathrm{CO}_{2} / \mathrm{CH}_{4}$ separation process, Heliyon, 5 (7), e02183.

[18] Hu, Y.L., and Fang, D., 2016, Preparation of silica supported ionic liquids for highly selective hydroxylation of aromatics with hydrogen peroxide under solvent-free conditions, J. Mex. Chem. Soc., 60 (4), 207-217.

[19] Gu, Y., Zhang, J., Duan, Z., and Deng, Y., 2005, Pechmann reaction in non-chloroaluminate acidic ionic liquids under solvent-free conditions, $A d v$. Synth. Catal., 347 (4), 512-516.

[20] Trubiano, G., Borio, D., and Errazu, A., 2007, Influence of the operating conditions and the external mass transfer limitations on the synthesis of fatty acid esters using a Candida antarctica lipase, Enzyme Microb. Technol., 40 (4), 716-722.

[21] Ratti, R., 2014, Ionic Liquids: Synthesis and applications in catalysis, $A d v$. Chem., 2014, 729842.

[22] Salih, N., and Salimon, J., 2021, A Review on ecofriendly green biolubricants from renewable and sustainable plant oil sources, Biointerface Res. Appl. Chem., 11 (5), 13303-13327.

[23] Ishak, Z.I., Sairi, N.A., Alias, Y., Aroua, M.K.T., and Yusoff, R., 2017, A review of ionic liquids as catalysts for transesterification reactions of biodiesel and glycerol carbonate production, Catal. Rev. Sci. Eng., 59 (1), 44-93.

[24] Neto, B.A.D., and Spencer, J., 2012, The impressive chemistry, applications and features of ionic liquids: Properties, catalysis \& catalysts and trends, J. Braz. Chem. Soc., 23 (6), 987-1007.

[25] Salimon, J., Salih, N., and Yousif, E., 2012, Industrial development and applications of plant oils and their biobased oleochemicals, Arabian J. Chem., 5 (2), 135-145. 